\title{
correspondence
}

\section{Confusion over Article 8}

W e enjoyed reading Andrea Rinaldi's article, 'Adopting an orphan' (EMBO Rep 6: 507-510), on regulations that aim to stimulate the research and development of medicines for rare diseases. We would like to congratulate the author on the quality of the article in general and on highlighting this important health problem.

However, Rinaldi stated that Emerging Biopharmaceutical Enterprises (EBE) and EuropaBio propose in their White Paper of March 2005, Towards an O ptimal O rphan Medicinal Products (OMP) Framework in Europe, that "Article 8 ... should be eliminated...". We would like to correct this quote because it is misleading with regard to the position and recommendations of EBE and EuropaBio as detailed in our W hite Paper. In fact, we do not believe that Article 8 , which regulates the extent of market exclusivity for orphan drugs, should be eliminated in building a European framework for orphan medicines.

O ur White Paper actually states that EBE and EuropaBio believe that "The confusion created around the potential reduction of the 10-year market exclusivity laid down in Article 8(2) should be eliminated...". This is a vital difference for two reasons. First, there is confusion at present in the interpretation of Article 8(2), caused in part by different versions in the various EU languages and in part by the fact that the provision is interpreted in a way that was not anticipated at the time of its drafting. This leads to a potential weakening of the incentives, particularly with regard to market exclusivity. Indeed, we believe that it is this confusion, rather than the Article itself, that should be eliminated to make the incentives clear and predictable and to stimulate more research into new treatments.

Second, we do not advocate the removal of any Article from the Regulation, merely a better application of its spirit. Rather than reviewing the text at this early stage in the Regulation's existence, it makes more sense to ensure the uniform and continued application of its provisions so as to stimulate research, development and access to therapies for rare diseases.

The Orphan Medicines Regulation, thanks to its carefully balanced incentives, has successfully fostered the development of various new medicines for rare diseases in its first five years of operation. But at this stage, it is important to stimulate and reward further investment in research to create even more treatments for patients who need them. Furthermore, we should also ensure that medicines, once approved, reach these patients. This will not only help people in need but also stimulate more research and knowledge-based economic activities in Europe, as is being called for by the European Commission.

\section{Erik Tambuyzer is Chair of theEBE/ EuropaBio Orphan Medicines Task Force. E-mail: erik.tambuyzer@genzyme.com \\ doi:10.1038/sj.embor.7400485}

